\title{
Experimental Study on the Influence of Curing Conditions on Capillary Absorption of Concrete
}

\author{
Li-Cheng Wang, Bao-Juan Cheng, and Jiu-Wen Bao \\ State Key Laboratory of Coastal and Offshore Engineering, Dalian University of Technology, \\ Dalian 116024, China
}

\begin{abstract}
Both the hardening process and formation of microstructure of concrete are significantly influenced by the curing condition. The capillary absorption of concrete is closely related to the structure and distribution of the pores within the material. This paper presents an experimental study on the influence of four curing conditions, i.e., standard curing, natural curing, water curing, and sealed curing, on the capillary absorption of normal concrete. Compressive strength tests on the cylinder specimens that are core drilled from concrete slabs are carried out. The "pie" samples cut from three different locations along the height direction of cylinder specimens are then conducted to measure the ultrasonic pulse velocity (UPV) and porosity, which quantitatively characterize the internal state of concrete after 28 days initial curing. In order to realize the continuous observation of water absorption testing, an improved gravimetrical test setup for measuring the sorptivity (the rate of water absorption) of concrete is designed to investigate capillary absorption of the "pie" samples. The experimental results indicate that the curing condition has an important influence on compressive strength, ultrasonic pulse velocity, and porosity of concrete. The temperature and relative humidity are the key factors to ensure strength development during the curing procedure and to determine the internal pore structure and the compactness of concrete. For the same curing conditions, the cumulative water content, sorptivity, and porosity of concrete gradually decrease with the increase of distance from the surface, but the ultrasonic pulse velocity reverses.
\end{abstract}

\section{INTRODUCTION}

The need for adequate curing is widely recognized as one of the essential step to achieve the optimum mechanical performance and durability of concrete structures (Ibrahim, Shameem, Al-Mehthel, \& Maslehuddin, 2013; Radlinski \& Olek, 2015; Shafiq \& Cabrera, 2004). Both the hardening process of cement paste and formation of microstructure within concrete are significantly influenced by the curing condition. Furthermore, the capillary absorption of concrete, which is one of important factors to assess the durability of concrete, is closely related to the structure and distribution of the pores within the material, because the pore network in the cement paste matrix or microcracks can provide transport path for water or aggressive agents (i.e., chloride ions, sulfate, oxygen, carbon dioxide, etc.) (Hall, 1989; Yang, Weiss, \& Olek, 2006). Breier and Kern (1997) pointed out that the improper curing condition has a much larger influence on the resistance of aggressive agent and capillary absorption than on tensile strength of low watercement ratio $(\mathrm{w} / \mathrm{c})$ concrete. On the other hand, due to the big difference between laboratory operating environment and construction site conditions, the mechanical properties of concrete (or durability index) tested in the laboratory are often not representative of the real situation in the actual concrete structure. Therefore, in order to provide a favorable basis for the service life and durability assessment of concrete, it is of utmost significance to investigate the influence of curing conditions on capillary absorption of concrete.

Water penetration into concrete can facilitate the ingress of aggressive species, regarding the principal transfer carrier, and it is mainly governed by capillary absorption, which is caused by the surface tension of pore liquid within the concrete. Many researchers pointed out that the internal pore structure of concrete, its size distribution, and the microcracks within concrete, which can be influenced by curing conditions, determine the rate of capillary absorption (Hall, 1989; Martys \& Ferraris, 1997; Yang et al., 2006). As a result of this, in most previous studies, the sorptivity is widely used to characterize the water absorption property by capillary suction since it is a well-defined physical parameter (Wang \& Ueda, 2011) and could be easily measured by means of the gravimetric technique (Lockington, 1993) (see Figure 1). However, the traditional gravimetric method recommended in ASTM C1585 (ASTM, 2004) could not avoid the error caused by manually wiping the sample at certain time intervals and also not ensure the continuity of water absorption process. 


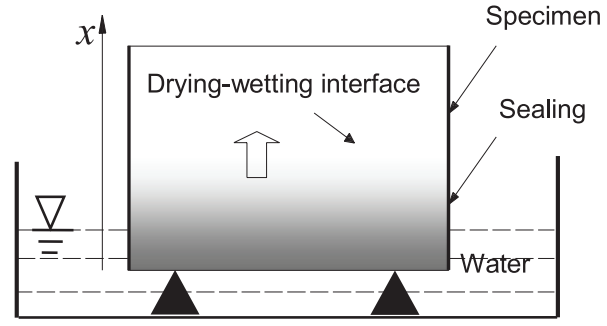

Figure 1. The schematic diagram of capillary absorption by the gravimetric method.

In the present paper, an experimental study was conducted to investigate the influence of four kinds of curing conditions, i.e., standard curing, natural curing, water curing, and sealed curing, on the capillary absorption of normal concrete by means of an improved gravimetrical test setup, which can realize the real-time observation of water absorption rate. The cylinder specimens that are core drilled from concrete slabs for a series of curing conditions are used to conduct the 28 days compressive strength test. The ultrasonic pulse velocity and porosity are utilized to quantitatively characterize the internal state of concrete after 28 days initial curing, and then the rate of capillary absorption (sorptivity) through concrete is regarded as the well-defined physical parameter to assess the durability performance of concrete. The cylinder specimens were thus cut into the "pie" samples of three different locations along the height direction to measure the ultrasonic pulse velocity, porosity, and cumulative water content.

\section{EXPERIMENTAL PROCEDURE}

\subsection{Materials and specimen preparation}

A group of water absorption experiments were designed and conducted on concrete samples under different curing conditions. The concrete was designed with water/cement $(\mathrm{w} / \mathrm{c})$ ratio of 0.5 . Ordinary Portland cement 42.5R (type CEM based on the Chinese code) was used. A locally available limestone aggregate with a maximum size of $20 \mathrm{~mm}$ was used as the coarse aggregate. A locally available river sand with the fineness modulus of 2.67 and apparent specific gravity of $1450 \mathrm{~kg} / \mathrm{m}^{3}$ was used as the fine aggregate. In addition, a water-reducing admixture was added at $0.2 \%$ by weight of cement to achieve a slump with the range of approximately $65-80 \mathrm{~mm}$. Details of the mixture proportion are listed in Table 1. In order to avoid the difference of specimens caused by the vibrating, stirring, and initial shrinking, the concrete slabs were cast in the wood mold with the dimensions of $500 \mathrm{~mm} \times 500 \mathrm{~mm} \times 120 \mathrm{~mm}$ (see Figure 2) and vibrated on a vibrating table for the same time to ensure the optimum compaction
Table 1. Mix proportion of concrete specimens.

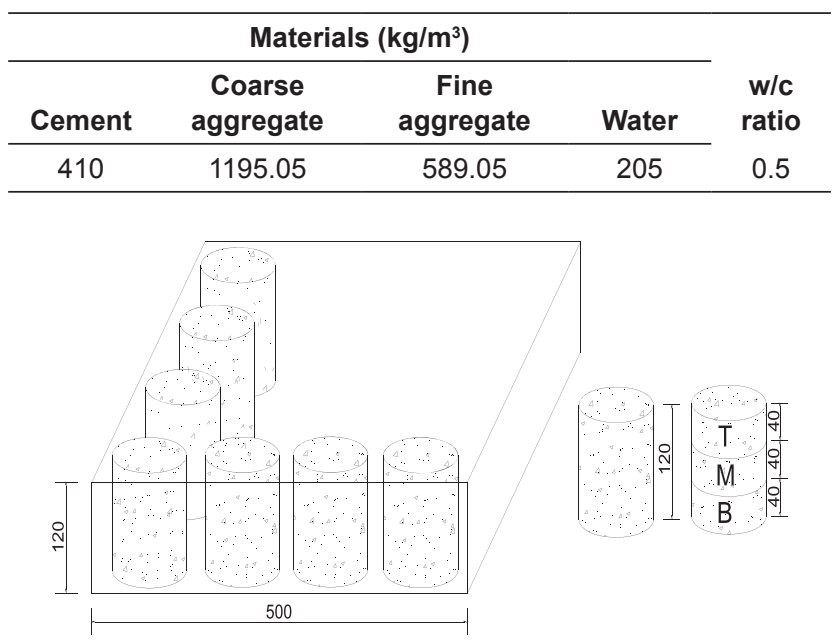

Figure 2. The casting and molding of specimens.

\subsection{Curing conditions}

To investigate the effect of curing conditions on capillary absorption of concrete, four curing methods, i.e., standard curing, natural curing, water curing, and sealed curing condition, were applied to the specimens, as shown in Table 2. Initially (from the time of casting until demolding), all specimens (only the top surface) were cured in a standard laboratory condition at $23 \pm 2^{\circ} \mathrm{C}$ and more than $90 \% \mathrm{RH}$. After demolding (about $24 \mathrm{~h}$ ), the remaining surfaces of the specimens (except for the bottom surface) were carried out under the respective curing condition.

Table 2. Curing conditions and compressive strength.

\begin{tabular}{|c|c|c|c|}
\hline Curing types & $\begin{array}{c}\text { Ambient } \\
\text { temperature }\end{array}$ & Conditions & $\begin{array}{c}\text { 28-day } \\
\text { compressive } \\
\text { strength (MPa) }\end{array}$ \\
\hline Standard curing & $23 \pm 2^{\circ} \mathrm{C}$ & $\begin{array}{l}\mathrm{RH} \text { higher } \\
\text { than } 90 \%\end{array}$ & 39.96 \\
\hline Natural curing & $12 \pm 3^{\circ} \mathrm{C}$ & $\begin{array}{l}\text { Sprinkling } \\
\text { water twice }\end{array}$ & 33.36 \\
\hline Water curing & $12 \pm 3^{\circ} \mathrm{C}$ & $\begin{array}{l}\text { Immerged } \\
\text { into water }\end{array}$ & 31.03 \\
\hline Sealed curing & $12 \pm 3^{\circ} \mathrm{C}$ & $\begin{array}{l}\text { Sealed by } \\
\text { plastic sheet }\end{array}$ & 28.16 \\
\hline
\end{tabular}

\subsection{Testing procedures}

Aftera period of 28 days curing, six cylindrical specimens in $120 \mathrm{~mm} \times 100 \mathrm{~mm}$ diameter were core drilled from the concrete slabs for the different curing conditions. Three cylinder specimens of the respective curing conditions were then used to conduct the compressive strength test. The rest was cut into the "pie" samples along the height direction of the cylinder specimens followed the solid lines in Figure 2, i.e., top ( $T$ ), middle $(\mathrm{M})$, and bottom (B). These samples were, 
respectively, carried out the measurement of porosity and ultrasonic pulse velocity. The mass deviation of sample weight under drying and saturated state was used to calculate the porosity. Five points of "pie" sample were chosen to measure the ultrasonic pulse velocity (see Figure 3 ), and the average velocity of these points was adopted to analyze the effect of curing conditions on the internal state of concrete.
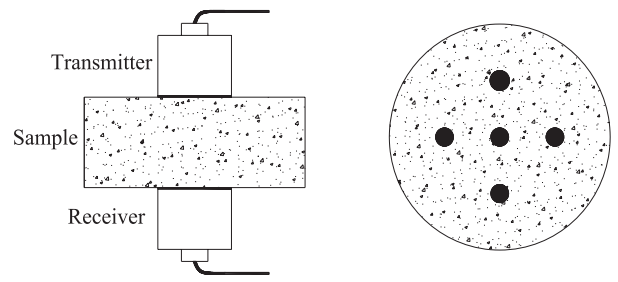

Figure 3. Ultrasonic pulse velocity test.

Water absorption is adopted to determine the amount of water absorbed under specified conditions, which indicates the degree of porosity of a material. To overcome the disadvantage of traditional gravimetric method, the improved test setup for capillary absorption is designed, as shown in the Figure 4. The apparatus consists of a capillarity cell and a scaled glass tube for measuring the volume of water taken into the concrete sample. The capillarity cell is made of high-density polyethylene, which is easy to cut and assemble (Wang \& $\mathrm{Li}, 2014)$. A feed water tube controlled by a valve is installed on the side opposite to the scaled glass tube in order to maintain sufficient water content in the cell. Water content reduction in the cell equals to that absorbed by the sample, and its value is continuously recorded by the horizontal scaled tube at various time intervals during testing. The cumulative water content $i$ of concrete for different curing conditions can be calculated based on the recorded test data as

$$
i=\frac{\Delta m}{\rho_{\mathrm{w}} A_{\mathrm{c}}}
$$

where $\Delta m$ is the weight of absorbed water at the given time $(\mathrm{g}) ; A_{\mathrm{c}}$ is the cross-sectional area of the "pie" sample $\left(\mathrm{mm}^{2}\right) ; \rho_{\mathrm{w}}$ is the density of water $\left(\mathrm{g} / \mathrm{mm}^{3}\right)$. The relationship between the cumulative water content $i$ and sorptivity $S$ (the rate of capillary water absorption) is often expressed as

$$
i=S \sqrt{t}+b
$$

where $b$ is a correction term to account for the rapid uptake of water when the sample initially makes contact with water (Hall, 1989); $t$ is the water absorbed time. The volume of water absorbed per unit crosssectional area at each time interval was evaluated and the sorptivity determined from the slope of the graph of the water absorbed against the square root of time.

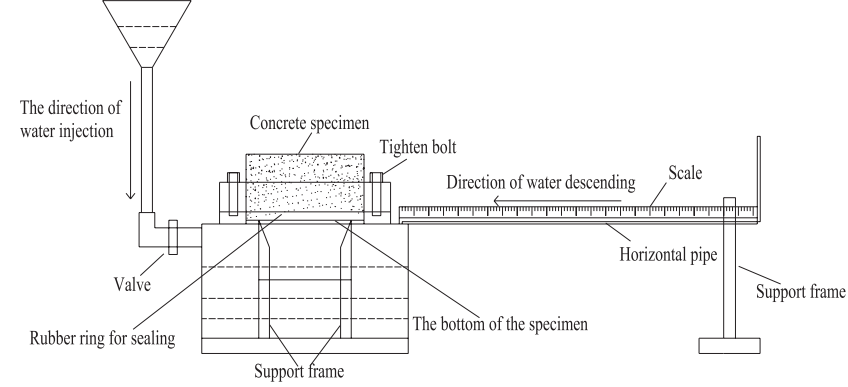

Figure 4. Improved test setup for capillary absorption.

Before exposure to water absorption test, the "pie" samples under four kinds of curing conditions were oven dried at $105^{\circ} \mathrm{C}$ to constant weight. The cutting face for all the "pie" samples was used to contact water source, and the lateral face was sealed by the epoxy glue to ensure the one dimensional water absorption. For each curing condition, the mean cumulative water content of three samples with the corresponding location were calculated and adopted to analyze the effect of curing condition on sorptivity obtained by linear fitting method.

\section{RESULTS AND DISCUSSION}

\subsection{Compressive strength}

The average compressive strength of three cylinder specimens for each curing condition after 28 days curing is shown in Table 2. The results suggest that the different curing conditions of concrete have a significant influence on the compressive strength. The highest compressive strength was obtained from the standard curing condition followed by the natural and water curing. It also indicates that initial strength development needs adequate humidity and suitable temperature to ensure the optimum hydration of cement paste during curing period. The lower curing temperature of natural and water curing condition reduces the hydration rate of cement paste and makes compressive strength lower than that of standard curing. The relative humidity is the dominant factor of concrete curing at the certain range of temperature. For the sealed curing of concrete specimen, lack of external water providing leads to lower internal relative humidity of concrete and makes them rely on their own mixing water to conduct cement hydration, so that its compressive strength is lowest. It thus indicates that the optimum temperature and adequate relative humidity are the key factors to ensure strength development during the curing procedure.

\subsection{Ultrasonic pulse velocity (UPV) and porosity}

The results obtained from the ultrasonic pulse velocity and porosity test of "pie" samples under four curing 
conditions are given in Figure 5. It can be obviously found that the ultrasonic pulse velocity of top, middle, or bottom sample under standard curing condition is greater than that corresponding sample of other three curing conditions, while the smallest ultrasonic pulse velocity belongs to the sealed curing. Contrary to the ultrasonic pulse velocity results, the highest porosities of top and middle samples are sealed curing, while the porosity of standard curing is smallest. However, the porosity for the bottom sample under the standard curing condition is greater than that of sealed curing. Furthermore, the variation of the average ultrasonic pulse velocity versus average porosity at the different locations (Top, Middle, and Bottom) is shown in the Figure 5(c). Generally, the above results suggest that the compactness of concrete is related to the curing condition. From the viewpoint of curing mechanism, the moisture supply of concrete outside can promote the hydration procedure of cement paste within concrete. Similarly, the better curing quality of concrete depends on the optimum temperature and relative humidity.

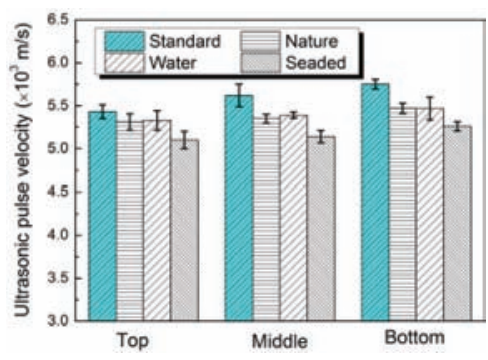

(a)

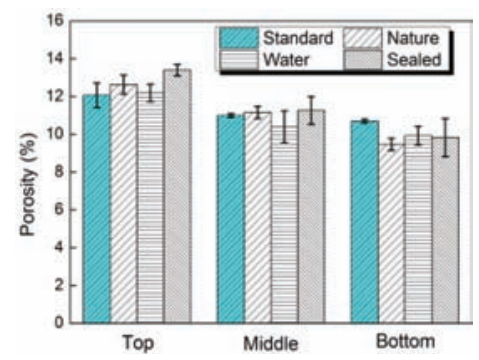

(b)

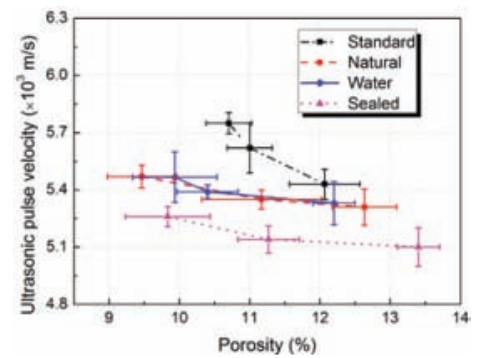

(c)

Figure 5. The ultrasonic pulse velocity and porosity under different curing conditions.

\subsection{Cumulative water content}

Figure 6 shows the cumulative water content of concrete specimens (top, middle, and bottom) for various curing conditions. The results of the same

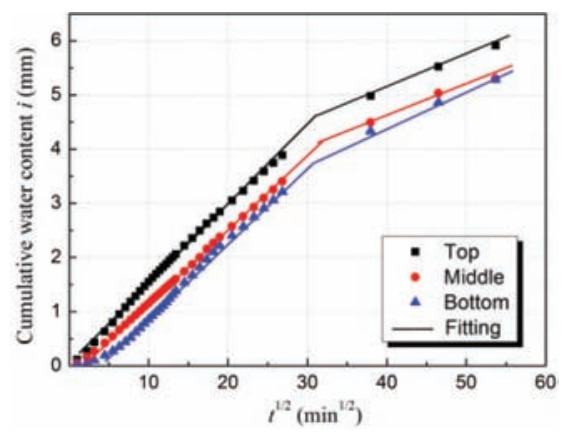

(a) Standard curing

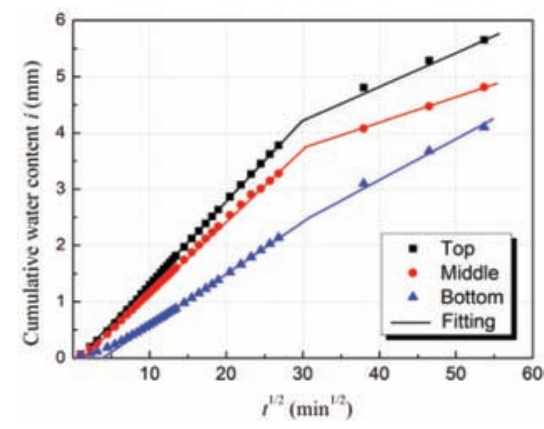

(b) Natural curing

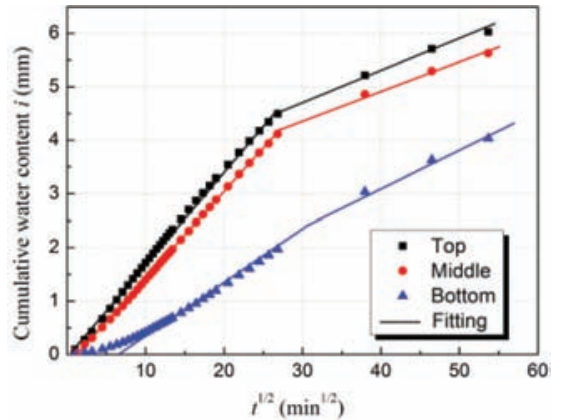

(c) Water curing

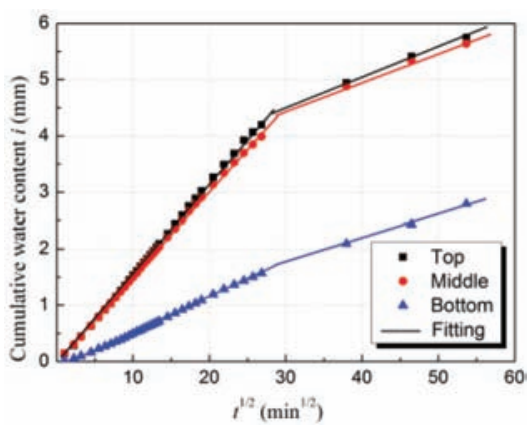

(d) Sealed curing

Figure 6. Cumulative water content of specimens under various curing conditions. 
curing condition indicate that the cumulative water contents at three different locations at same elapsed time was $i_{\mathrm{T}}>i_{\mathrm{M}}>i_{\mathrm{B}}$. It is attributed the fact that the cement paste of top sample is more than that of middle (or bottom) location during casting due to the vibrating, so that a relatively larger amount and bigger size of pores distributes at the top location due to the cement paste hydration in the curing period. Similarly, it is found that the curves for the majority of the samples tested, regardless of the curing method used, consist of two linear portions. Yang et al. (2006) pointed out that each portion can be attributed to different transport mechanisms for water movement in concrete. The initial linear part corresponds to the rapid saturation of capillary pores immediately after exposure to water, and the much longer second linear portion is due to the slower filling of air voids with water. It thus seems reasonable and necessary to treat and analyze the water absorption curves separately in order to accurately compare sorptivity under different curing conditions.

\subsection{Sorptivity}

Figure 7 shows the slopes of the two linear portions of the $i-t^{1 / 2}$ curves under four kinds of curing conditions, which are defined as the initial sorptivity $\left(S_{1}\right)$ and second sorptivity $\left(S_{2}\right)$ (Wang \& Li, 2014). Obviously, the initial sorptivity of each location for the same curing condition

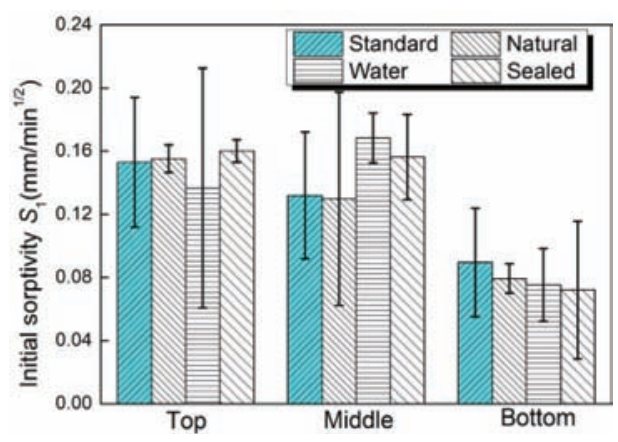

(a)

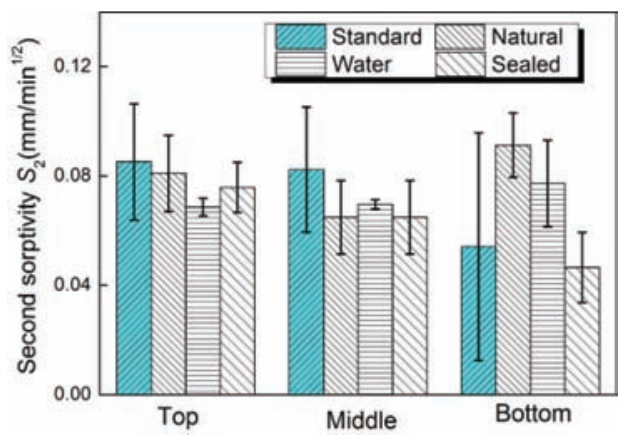

(b)

Figure 7. Initial and second sorptivity of concrete under various curing conditions. is greater than the corresponding location of second sorptivity. Generally, the initial and second sorptivity of bottom sample under sealed curing is lowest than other curing conditions. It can be attributed to more of the interfacial transition zone between aggregate and mortar at the bottom of specimen and lack of water supply during hydration process under sealed curing condition. The effect of sample location on the initial sorptivity is obvious $\left(S_{1 \mathrm{~T}}>S_{1 \mathrm{M}}>S_{1 \mathrm{~B}}\right)$, while the second sorptivity has no regular change. Similarly, the curing condition (except sealed condition) has no regular influence on sorptivity. However, the experimental results can suggest that the sorptivity of concrete is closely related to the curing condition.

\subsection{Relative curing efficiency (RCE)}

Relative curing efficiency is used to quantitatively evaluate the effect of the curing methods applied in the present paper and the difference between them (Radlinski \& Olek, 2015). In order to analyze the difference between laboratory operating environment and construction site conditions, the standard curing was chosen as the reference curing method. The formula of relative curing efficiency $\eta$ can be given as

$$
\eta=\left(\frac{I}{I_{\text {ref }}}\right)^{m} \times 100 \%
$$

in which $I$ and $I_{\text {ref }}$ are, respectively, the corresponding result of test index for evaluated and reference curing method; the parameter $m(-1$ or +1$)$ is used for different properties to ensure that the RCE values approaching 1 are consistently associated with high curing efficiency for all properties. The geometric average is adopted to investigate the effect of each curing method on the evaluated properties as

$$
\bar{\eta}=\left(\prod_{i=1}^{n} \eta\right)^{1 / n}
$$

in which $n$ is the number of the evaluated properties. Figure 8 presents the RCE values of the evaluated properties for natural, water, and sealed curing conditions.

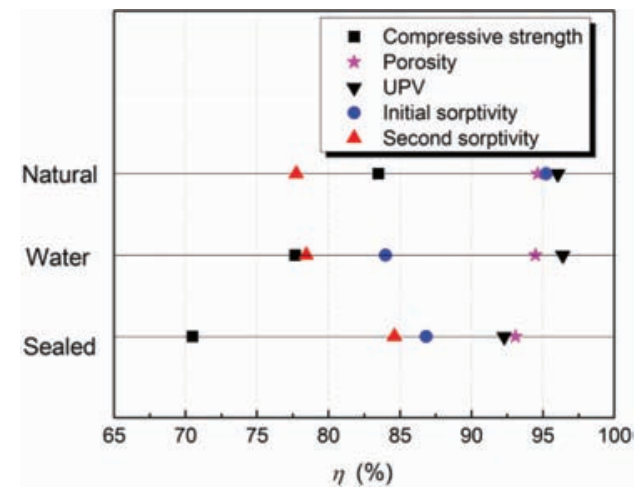

Figure 8. Relative curing efficiency for various curing conditions. 
Generally, with consideration of the combination of compressive strength, porosity, ultrasonic pulse velocity, initial and second sorptivity, the average relative curing efficiency of these curing methods can be then, respectively, calculated to be $89.10,85.83$, and $85.04 \%$.

\section{CONCLUSION}

An improved gravimetrical test apparatus for measuring the sorptivity of concrete was designed to investigate the effect of curing condition on water absorption. The cylindrical specimens that are core drilled from concrete slabs for a series of curing conditions were used to carry out the compressive strength test of a period of 28 days curing, and then the ultrasonic pulse velocity and porosity were conducted by the "pie" sample cut from the cylinder specimens. The following conclusions were obtained based on the results of the experimental study.

(1) The curing condition has an important influence on the compressive strength, ultrasonic pulse velocity, and porosity. The temperature and relative humidity are two key factors to ensure strength development during the curing procedure. The ultrasonic pulse velocity and porosity of specimens depend on the hydration process of the cement paste within concrete, and the ultrasonic pulse velocity for the same curing condition decreases with the increase of porosity.

(2) According to the cumulative absorbed water curve $\left(i-t^{1} / 2\right)$, the two linear portions of sorptivity under four kinds of curing conditions are obviously reflected. The initial sorptivity (S1) of each location for the same curing condition is greater than the corresponding location of second sorptivity (S2), while the curing condition (except sealed condition) has no regular influence on sorptivity.

\section{ACKNOWLEDGMENTS}

This study was supported by the National Natural Science Foundation of China (Grant No. 51378090) and the National Key Basic Research Program of China (973 Program) (No. 2015CB057701; No. 2015CB057703).

\section{REFERENCES}

ASTM. (2004). ASTM C1585: Standard test method for measurement of rate of absorption of water by hydraulic-cement concretes. West Conshohocken, PA: ASTM International.

Breier, H., \& Kern, R. (1997). Efficiency of curing methods for high-strength concrete. Darmstadt Concrete, 12, 123-134.

Hall, C. (1989). Water sorptivity of mortars and concretes: A review. Magazine of Concrete Research, 41(147), 51-61.

Hall, C. (2007). Anomalous diffusion in unsaturated flow: Fact or fiction? Cement and Concrete Research, 37(3), 378-385.

Ibrahim, M., Shameem, M., Al-Mehthel, M., \& Maslehuddin, M. (2013). Effect of curing methods on strength and durability of concrete under hot weather conditions. Cement and Concrete Composites, 41, 60-69.

Lockington, D. (1993). Estimating the sorptivity for a wide range of diffusivity dependence on water content. Transport in Porous Media, 10(1), 95-101.

Martys, N. S., \& Ferraris, C. F. (1997). Capillary transport in mortars and concrete. Cement and Concrete Research, 27(5), 747-760.

Radlinski, M., \& Olek, J. (2015). Effects of curing conditions on the properties of ternary (Ordinary Portland Cement/Fly Ash/Silica Fume) concrete. ACI Materials Journal, 112(1), 49-58.

Shafiq, N., \& Cabrera, J. G. (2004). Effects of initial curing condition on the fluid transport properties in OPC and fly ash blended cement concrete. Cement and Concrete Composites, 26(4), 381-387.

Wang, L. C., \& Li, S. H. (2014). Capillary absorption of concrete after mechanical loading. Magazine of Concrete Research, 66(7/8), 420-431.

Wang, L. C., \& Ueda, T. (2011). Mesoscale modeling of water penetration into concrete by capillary absorption. Ocean Engineering, 38(4), 519-528.

Yang, Z. F., Weiss, W. J., \& Olek, J. (2006). Water transport in concrete damaged by tensile loading and freeze-thaw cycling. Journal of Materials in Civil Engineering, 18(3), 424-433. 